\title{
Resolution of Muscle Inflammation After Tumor Removal in a Woman with Paraneoplastic Dermatomyositis
}

GUIDO PRIMIANO, MD; DOMENICO PLANTONE, MD; DONATO SAUCHELLI, MD; CRISTINA CUCCAGNA, MD; ROSARIA RENNA, MD; RAFFAELE IORIO, MD; SERENELLA SERVIDEI, PhD, Department of Neurology, Catholic University of the Sacred Heart, Rome, Italy. Address correspondence to Dr. D. Plantone, Department of Neurosciences, Institute of Neurology, Catholic University of the Sacred Heart, Largo Gemelli 8, 00168 Rome, Italy. E-mail: domenicoplantone@hotmail.com. J Rheumatol 2012;39:2359-60; doi:10.3899/jrheum.120806

The paraneoplastic association of dermatomyositis (DM) and underlying breast cancer is well established ${ }^{1,2}$. This report confirms the diagnostic and therapeutic value of searching for malignancy in patients with $\mathrm{DM}^{3,4}$.

A 33-year-old woman developed subacute severe proximal muscle weakness, dysphagia, respiratory failure, skin lesions on the forehead, and purplish discoloration around the upper eyelid, with ulcerating nodules in the dorsal surface of the distal phalanges. Creatine kinase levels were elevated (8000 IU/1, normal 30 to 190). Electromyography (EMG) showed short-duration, small-amplitude, polyphasic motor units and spontaneous activity (fibrillation potentials and positive sharp waves) in rectus femoris muscle bilaterally. Muscle magnetic resonance imaging (MRI) showed hyperintensity of vastus medialis and rectus femoris muscles bilaterally on $\mathrm{T} 2$-weighted short-tau inversion recovery (Figure 1).

Muscle biopsy confirmed the clinical diagnosis of DM with perifascicular distribution of atrophic, degenerating, and regenerating myofibers and abnormal capillary morphology and capillary loss. Immunohistochemistry showed an inflammatory process characterized by endomysial infiltrates of mononuclear cells with prevalence of CD8+ cytototoxic T-lymphocytes, perivascular CD4+ rich infiltrates, strong membrane immunosignal for MHC-1, and deposition of the C5b-9 membrane attack complex on endothelial cells. Thoracic computed tomography revealed a lesion in the left breast that a biopsy demonstrated to be a papillary carcinoma. After surgical removal of the tumor, chemotherapy, and immunosuppressive treatment, the patient experienced complete resolution of symptoms and complete regression of EMG and muscle MRI abnormalities in 6 months (Figure 2).

We confirm the diagnostic and therapeutic value of searching for malignancy in patients with $\mathrm{DM}^{3,4}$ and that muscle abnormalities may completely regress after adequate treatment of the underlying tumor.

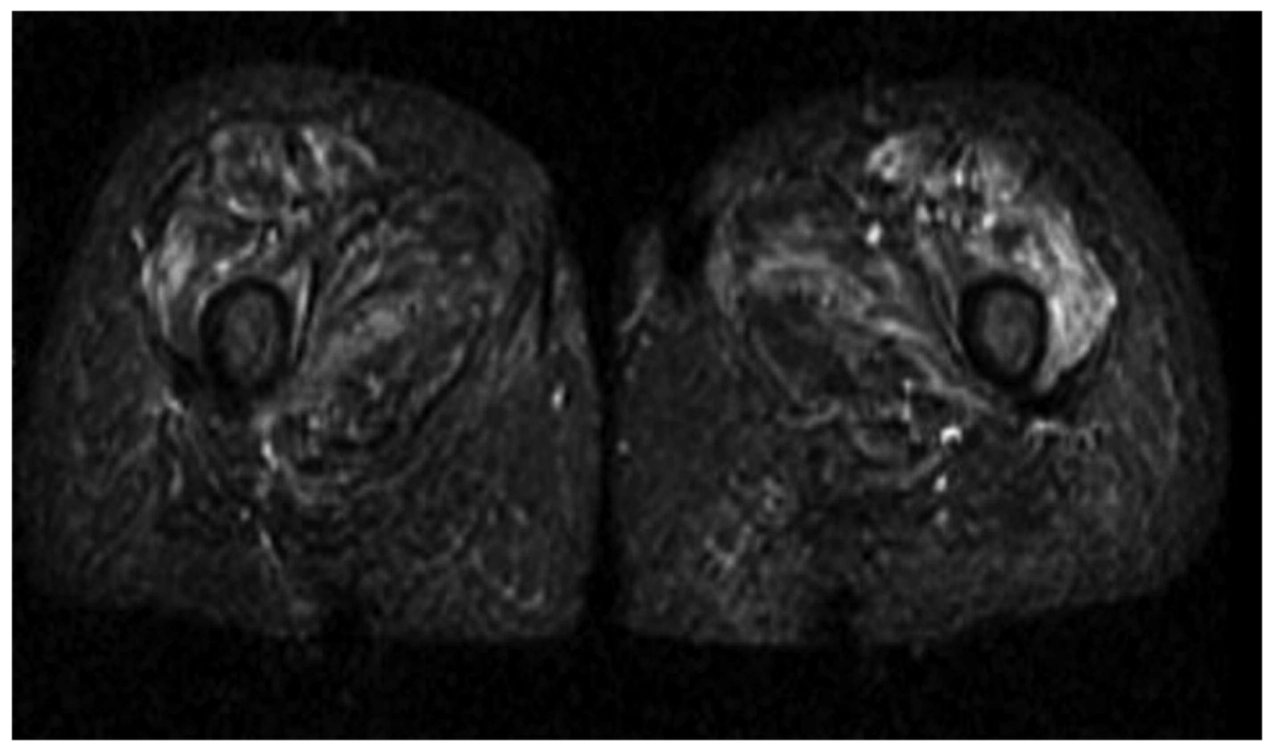

Figure 1. Muscle MRI. T2-weighted short-tau inversion recovery axial image through the proximal thigh, showing increased signal intensity in vastus medialis and rectus femoris muscles bilaterally, due to edema and inflammation. 


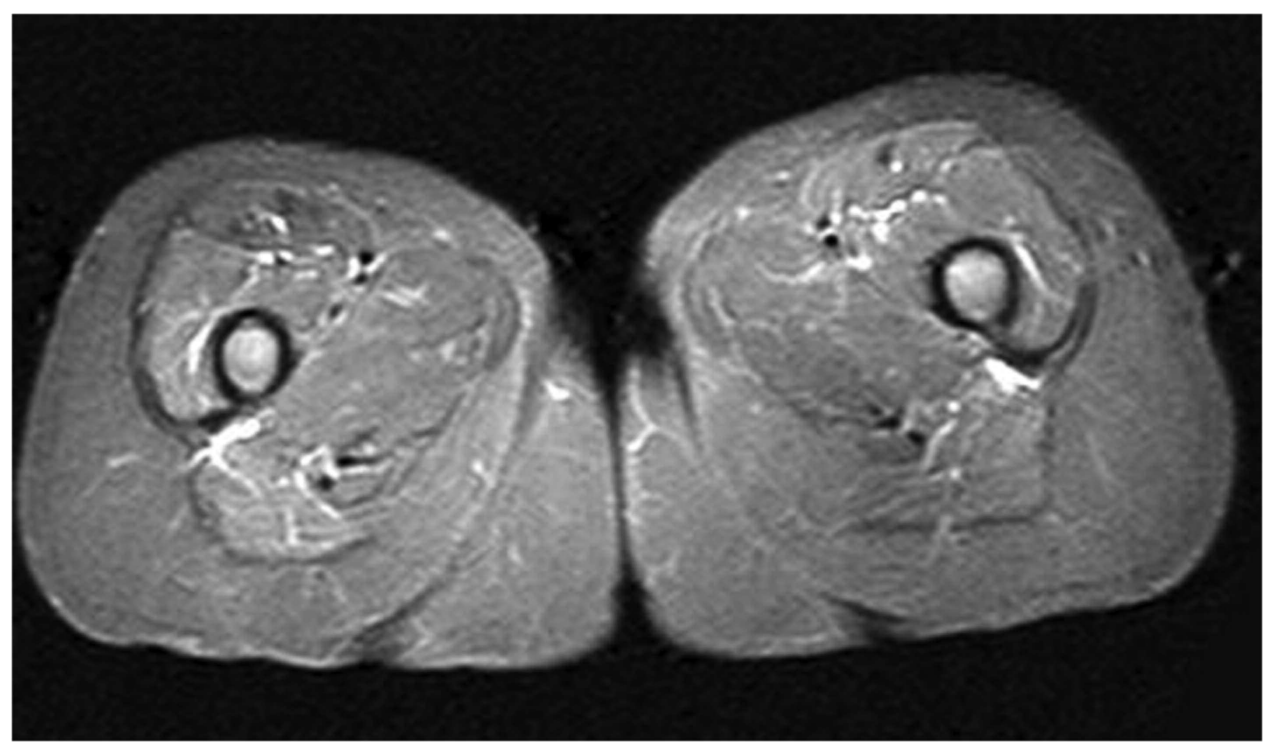

Figure 2. Muscle MRI. Short T1 inversion recovery turbo spin-echo imaging through the proximal thigh after surgical, chemotherapy, and immunosuppressive treatments, showing resolution of abnormalities.

\section{REFERENCES}

1. Sigurgeirsson B, Lindelof B, Edhag O, Allander E. Risk of cancer in patients with dermatomyositis or polymyositis. A population-based study. N Engl J Med 1992;6:363-7.

2. Hill CL, Zhang Y, Sigurgeirsson B, Pukkala E, Mellemkjaer L, Airio A, et al. Frequency of specific cancer types in dermatomyositis and polymyositis: A population-based study. Lancet 2001;357:96-100.
3. Mahil S, Marks D, McCormack M, Rahman A. Dermatomyositis. Br J Hosp Med 2012;73:C18-22.

4. Zampieri S, Valente M, Adami N, Biral D, Ghirardello A, Rampudda ME, et al. Polymyositis, dermatomyositis and malignancy: A further intriguing link. Autoimmun Rev 2010; 9:449-53. 